\title{
White bile in patients with malignant biliary obstruction is an independent factor of poor survival
}

\section{(ㄷ)(요 $\odot$}

\author{
Authors \\ Sockalingum $^{3}$, Roselyne Garnotel ${ }^{3}$, Gérard Thiefin ${ }^{1,3}$ \\ Institutions \\ 1 Department of Hepato-Gastroenterology and Digestive \\ Oncology, Reims University Hospital, Reims, France \\ 2 Clinical Research Unit, Reims University Hospital, Reims, \\ France \\ 3 Université de Reims Champagne-Ardenne, BioSpecT- \\ EA7506, Reims, France
}

Rosario D'almeida', Coralie Barbe², Valérie Untereiner ${ }^{3}$, Fidy Ramaholimihaso', Pascal Renard', Ganesh D.

submitted 24.4.2020

accepted after revision 21.9.2020

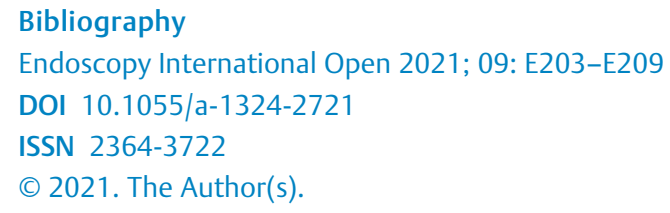
Commons Attribution-NonDerivative-NonCommercial License, permitting copying and reproduction so long as the original work is given appropriate credit. Contents may not be used for commecial purposes, or adapted, remixed, transformed or built upon. (https://creativecommons.org/licenses/by-nc-nd/4.0/)

Georg Thieme Verlag KG, Rüdigerstraße 14,

70469 Stuttgart, Germany

Corresponding author

Pr Gerard Thiéfin, Department of Hepato-Gastroenterology and Digestive Oncology, Reims University Hospital, 51092

Reims cedex, France

Fax: +33 26788836

gthiefin@chu-reims.fr

Supplementary material is available under https://doi.org/10.1055/a-1324-2721

\section{ABSTRACT}

Background and study aims White bile is defined as a colorless fluid occasionally found in the biliary tract of patients with bile duct obstruction. Its significance is not clearly established. Our objective was to analyze the prognostic value of white bile in a series of patients with biliary obstruction due to biliary or pancreatic cancer.

Patients and methods The study was conducted on a series of consecutive patients with malignant obstructive jaundice. They all underwent endoscopic retrograde cholangiopancreatography with collection of bile and biliary stent insertion. White bile was defined as bile duct fluid with bilirubin level $<20 \mu \mathrm{mol} / \mathrm{L}$. Univariate and multivariate analyses were performed to identify variables associated with overall survival (OS).

Results Seventy-three patients were included (32 pancreatic cancers, 41 bile duct cancers). Thirty-nine (53.4\%) had white bile. The mean bile duct bilirubin level in this group was $4.2 \pm 5.9 \mu \mathrm{mol} / \mathrm{L}$ vs $991 \pm 1039 \mu \mathrm{mol} / \mathrm{L}$ in patients with colored bile $(P<0.0001)$. In the group of 54 patients not eligible for surgery, the multivariate analysis demonstrated an association between the presence of white bile and reduced OS (HR 2.3, $95 \% \mathrm{Cl} 1.1-4.7 ; \mathrm{P}=0.02$ ). Other factors independently associated with OS were metastatic extension (HR 2.8, 95\% $\mathrm{Cl} 1.4-5.7)$ and serum total bilirubin (HR $1.003,95 \% \mathrm{Cl} 1.001-1.006)$. There was a significant inverse correlation between serum and bile duct bilirubin levels ( $r$ $=-0.43, \mathrm{P}=0.0001)$.

Conclusion White bile in patients with inoperable malignant biliary obstruction is an independent factor of poor survival.

\section{Introduction}

The presence of colorless and transparent fluid in the biliary tract of patients with bile duct obstruction has been reported as early as the beginning of the 20th century by surgeons [ 1 , 2] and more recently by endoscopists [3-5]. The term "white bile" has been coined to describe this entity. Although a misnomer, this term is conventionally used to describe a translucent bilirubin-free fluid to be differentiated from the white-colored purulent bile $[6,7]$. White bile is observed in patients with biliary obstruction of either benign or malignant origin. Biochemical analysis showed that white bile was nearly devoid of bilirubin and biliary acids [8-10].

The pathogenic mechanisms of white bile formation are still unclear. The initial hypothesis that white bile is observed only when the gallbladder is excluded $[1,11]$ has not been confirmed by subsequent clinical observations $[3,10]$. Whether white bile reflects impaired hepatocellular function and is asso- 
ciated with poorer prognosis is controversial $[10,12]$. Until recently, most cases were anecdotal observations or small series. In the most recent and best documented study [3], white bile was associated with worse survival in patients with inoperable malignant biliary obstruction. However, only 18 patients with white bile, 15 of them with gallbladder carcinomas, were included in this study.

Given this, the main objective of the present study was to revisit the question of the prognostic significance of white bile in a larger series of patients with biliary obstruction due either to biliary or pancreatic cancer and undergoing endoscopic biliary drainage.

\section{Patients and methods}

\section{Patients}

This study was conducted on a series of consecutive patients with malignant obstructive jaundice undergoing diagnostic and therapeutic endoscopic retrograde cholangiopancreatography (ERCP) in the Hepato-Gastroenterology Unit of Reims University Hospital. Patients were initially referred for jaundice or cholangitis. They had a complete clinical, biological and imaging evaluation including liver tests, ultrasound, abdominal computed tomography scan and/or magnetic resonance cholangiopancreatography. The diagnosis of extrahepatic cholestasis was made and ERCP was performed to obtain a precise diagnosis of the nature of the biliary obstruction and to decompress the biliary tract. The examination was conducted with a TJF duodenoscope (Olympus Optical, Tokyo, Japan) under general anesthesia. Bile duct was cannulated using a sphincterotome (Autotome, Boston Scientific, Natick, Massachusetts, United States) mounted on a guide wire (Life Partners Europe, Bagnolet, France). After insertion of the guidewire across the stenosis, the cannula was positioned above the biliary obstruction and about 5 to $10 \mathrm{~mL}$ of fluid was collected for cytology by gentle suction with a syringe, before any injection of contrast agent. All patients with previous contrast agent injection, even mild, were excluded. Then, depending on the endoscopist's decision, brush cytology (Cook Medical, Bloomington, Indiana United States) and biopsy (Endojaw FB-211K, Olympus Optical) were also performed. Finally, biliary drainage was obtained by insertion of a $10 \mathrm{~F}$ or $11.5 \mathrm{~F}$ Teflon stent (Cook Medical) or a covered or uncovered metallic prosthesis (Boston Scientific). In some patients, echoendoscopy (Olympus Optical Co.) was coupled to ERCP and when appropriate, puncture of a solid mass was performed for cytological and/or histological examination. After biliary decompression, patients were followed clinically and serum bilirubin was measured at different intervals according to clinician decision. The following data were retrospectively collected from the medical files: age, sex, serum bilirubin, results of cytological and pathological examination, type of cancer, level of obstruction, presence of metastasis, history of cholecystectomy, and modalities of surgical and medical treatment. Patient records were anonymized and de-identified prior to analysis. The database was constituted in accordance with the reference methodology MR004 of the Commission Na- tionale de l'Informatique et des Libertés ( $n^{\circ} 2206749$, 13/09/ 2018).

\section{Measurement of bile duct bilirubin}

Bile duct fluid collected during ERCP was sent to the laboratory in the following hour to 2 hours. It was centrifuged at 1500 revolutions/min for 5 minutes and the precipitate was collected, smeared on slides, fixed in methanol and stained with the Papanicolaou method for cytological evaluation. The remaining supernatant was retrieved, frozen, and stored in the dark at $-80^{\circ}$ $\mathrm{C}$ for further analysis. After thawing, total bilirubin in the bile duct fluid was measured by a diazo colorimetric method using the COBAS 8000 analyzer (Roche Diagnostics France). Previous studies on serum have reported that freezing at $-80^{\circ} \mathrm{C}$ did not affect total bilirubin measurement [13]. In addition, as bilirubin is sensitive to phototransformation, samples were sent to the laboratory and stored protected from light. White bile was defined by bile duct bilirubin level $<20 \mu \mathrm{mol} / \mathrm{L}$ and colored bile was defined as bile duct bilirubin $>20 \mu \mathrm{mol} / \mathrm{L}$.

\section{Follow-up and endpoints}

Survival time was defined as the time between ERCP and death. The primary endpoint was overall survival (OS). Patients alive at the end of the follow-up were censored. Patients lost during follow-up were censored at the date of the last contact. Secondary endpoints were to analyze: 1 ) the relationship between the presence of white bile and the level of biliary obstruction below or above the cystic convergence in non-cholecystectomized patients; and 2) the relationship between serum bilirubin and bile duct bilirubin levels.

\section{Statistical analysis}

Quantitative variables were reported as mean \pm standard deviation and qualitative data as number and percentage. OS was calculated from the date of ERCP to the date of death or censoring. The survival curves were established using the Kaplan-Meier method in population of patients with surgery and in population of patients without surgery. Variables associated with OS in the population of patients with surgery and in the population of patients without surgery were identified by univariate analyses using log rank tests and by multivariate analyses using a Cox proportional hazard model. Factors significant at the 0.10 level in univariate analysis were included in a stepwise regression multivariate analysis with entry and removal limits set at 0.10 . The correlation between serum and bile duct bilirubin levels was estimated using the Pearson's correlation coefficient.

$P<0.05$ was considered statistically significant. All statistical analyses were performed using SAS version 9.4 (SAS Inc, Cary, North Carolina, United States).

\section{Results}

\section{Patient characteristics}

A total of 73 patients were included. Thirty-two of them (43.8\%) had pancreatic cancer and 41 (56.2\%) bile duct cancer, including one with gallbladder cancer. The characteristics 
- Table 1 Characteristics of patients with white bile $(n=39)$ and colored bile $(n=34)$.

\begin{tabular}{|c|c|c|c|}
\hline Variable $^{1}$ & White bile $(n=39)$ & Colored bile $(n=34)$ & $P$ value \\
\hline Age (years), mean $\pm S D$ & $68.6 \pm 10.8$ & $68.6 \pm 12.1$ & 0.97 \\
\hline Sex ratio, $M / F, n$ & $22 / 17$ & $19 / 15$ & 0.96 \\
\hline History of cholecystectomy & $3(7.7)$ & $7(20.6)$ & 0.17 \\
\hline Serum total bilirubin, $\mu \mathrm{mol} / \mathrm{L}(\mathrm{md}=1)$ & $345 \pm 127$ & $210 \pm 134$ & $<0.0001$ \\
\hline Bile duct total bilirubin, $\mu \mathrm{mol} / \mathrm{L}$ & $4.2 \pm 5.9$ & $991 \pm 1040$ & $<0.0001$ \\
\hline \multicolumn{3}{|c|}{ Level of obstruction in non-cholecystectomized patients $(n=63)$ : } & \multirow[t]{4}{*}{0.16} \\
\hline - Below cystic duct convergence & $24 / 36(66.7)$ & $24 / 27(88.9)$ & \\
\hline - Above cystic duct convergence & $5 / 36(13.9)$ & $1 / 27(3.7)$ & \\
\hline - Hilar & $7 / 36(19.4)$ & $2 / 27(7.4)$ & \\
\hline Metastasis & $24(61.5)$ & $13(38.2)$ & 0.047 \\
\hline \multicolumn{3}{|l|}{ Type of prosthesis } & \multirow[t]{3}{*}{0.58} \\
\hline - Plastic & 15 & 11 & \\
\hline - Metallic & 24 & 23 & \\
\hline Surgical treatment & $7(18.0)$ & $12(35.3)$ & 0.09 \\
\hline Chemotherapy & $24(61.5)$ & $26(76.5)$ & 0.17 \\
\hline
\end{tabular}

of the whole population and the comparison between patients with pancreatic cancer and those with bile duct cancer are shown in the Supplementary Table 1.

All patients had jaundice at the time of ERCP, two of them with concomitant cholangitis (one patient with pancreatic cancer and colored bile and one with biliary cancer and white bile). The mean serum total bilirubin level was $283 \pm 145 \mu \mathrm{mol} / \mathrm{L}$. Thirty-nine patients (53.4\%) had white bile i. e., bile duct bilirubin $<20 \mu \mathrm{mol} / \mathrm{L}$. The mean bile duct bilirubin level in this group was $4.2 \pm 5.9 \mu \mathrm{mol} / \mathrm{L}$ compared to $991 \pm 1040 \mu \mathrm{mol} / \mathrm{L}$ in the group of patients with colored bile $(\mathrm{P}<0.0001)$. The characteristics of these two groups of patients are shown in $>$ Table 1. Age and sex ratio were not significantly different between the two groups. Serum total bilirubin level was significantly higher in patients with white bile $(345 \pm 127 \mu \mathrm{mol} / \mathrm{L})$ compared to patients with colored bile $(210 \pm 134 \mu \mathrm{mol} / \mathrm{L}, \mathrm{P}<0.0001)$. There was no significant difference in the type of prosthesis between patients with white bile and those with colored bile $(P=0.58)$. In five cases, initial endoscopic biliary drainage incompletely resolved jaundice, Percutaneous drainage was performed in three patients ( 2 patients with colored bile, 1 patient with white bile), a double surgical derivation in one (white bile patient), and a second procedure using metallic prosthesis to replace the biliary plastic prosthesis initially inserted in one (white bile patient). Patients with white bile more often had metastasis compared to patients with colored bile (61.5\% vs $38.2 \%, \mathrm{P}=0.047$ ). In the great majority of cases in both groups, evolution of cancer was the cause of death. In one patient with local recurrence of biliary cancer and peritoneal carcinosis, death was due to stroke (colored bile group). In another patient with biliary can- cer, death was due to myocardial infarction (colored bile group). Two other patients with biliary cancer were lost of follow-up with no information on the precise cause of death (one patient in the colored bile group and one patient in the white bile group).

\section{Survival analysis}

Cumulative survival was significantly shorter in patients with pancreatic cancer compared to patients with bile duct cancer $(P=0.02$, log rank test). Median survival was 9.6 months $(95 \%$ $\mathrm{Cl}$ : 5.6-15) in the whole population and 15.2 months $(95 \% \mathrm{Cl}$ : 5.5-31.3) and 7.7 months (95\% Cl: 4.1-10.1) in the groups of patients with bile duct cancer and pancreatic cancer, respectively ( $\triangleright$ Fig. 1 ).

Survival curves in the population of patients with intended curative surgery $(n=19)$ and those not eligible for surgery $(n=$ 54) are presented in $\mathbf{F i g . 2}$. Median survival was 41.5 months (95\% Cl: 18.7-94.8) in the population with surgery and 5.6 months ( $95 \% \mathrm{Cl}: 3.3-8.9$ ) in the population without surgery.

In the population with surgery, no factor was associated with OS ( Table 2). Median survival was 22.8 months (95\% Cl: 10.8 $94.8)$ in the "white bile" group $(n=7)$ and 26.5 months $(95 \% \mathrm{Cl}$ : 12.7-61.1) in the "colored bile" group $(n=12)(P=0.96)$.

In the population without surgery, as shown in - Fig. 3, cumulative survival was significantly poorer in patients with white bile $(n=32)$ compared with patients with colored bile $(n=22)(P$ $=0.003$, log rank test). Median survival was 2.9 months $(95 \% \mathrm{Cl}$ : $0.2-25.9)$ in the "white bile" group and 9.1 months $(95 \% \mathrm{Cl}$ : $1.1-55.2)$ in the "colored bile" group. In univariate analysis based on the log rank test ( $>$ Table 3 ), other factors associated 

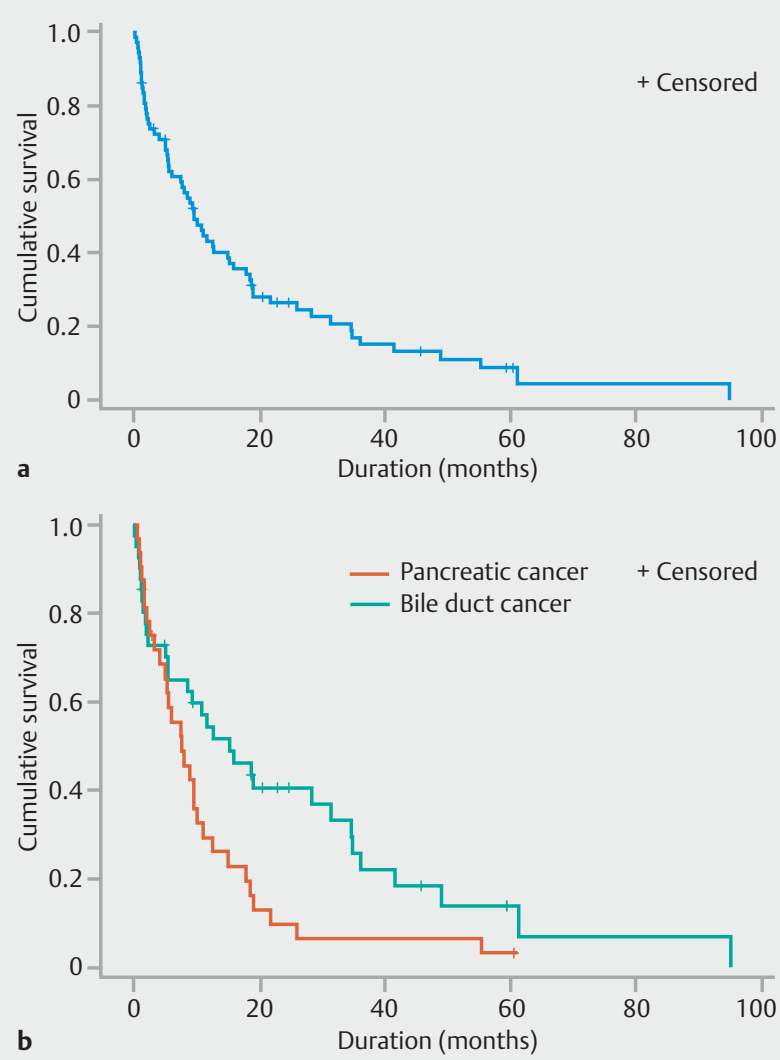

- Fig. 1 Kaplan-Meier survival curves. a For the whole population $(n=73)$. b For patients with biliary $(n=41)$ and pancreatic cancer $(n=32)(P=0.02$, log rank test).

with survival were metastatic extension of cancer $(P=0.0002)$ and serum total bilirubin $(P<0.0001)$. In multivariate analysis $(\triangleright$ Table 3 ), all these factors remained significant independent factors associated with OS: white bile (HR $2.3,95 \% \mathrm{Cl}$ : 1.14.7, $\mathrm{P}=0.02$ ), metastatic extension ( $\mathrm{HR} 2.8,95 \% \mathrm{Cl}: 1.4-5 ., \mathrm{P}$ $=0.003)$. and serum total bilirubin ( $\mathrm{HR} 1.003,95 \% \mathrm{Cl}: 1.001-$ $1.006, P=0.01)$.

\section{Impact of the level of bile duct obstruction on white bile formation}

White bile was observed both in cholecystectomized and noncholecystectomized patients (3/10 and 36/63 respectively). The relationship between the level of biliary obstruction and white bile formation was analyzed in the subgroup of non-cholecystectomized patients $(n=63)$. Fifty percent of patients $(24 /$ 48 ) with distal obstruction below the cystic convergence (i. e., with gallbladder connected to occluded biliary tract), presented with white bile at the time of ERCP versus 12/15 (80.0\%) patients with biliary obstruction above the cystic convergence $(P=0.04)$.

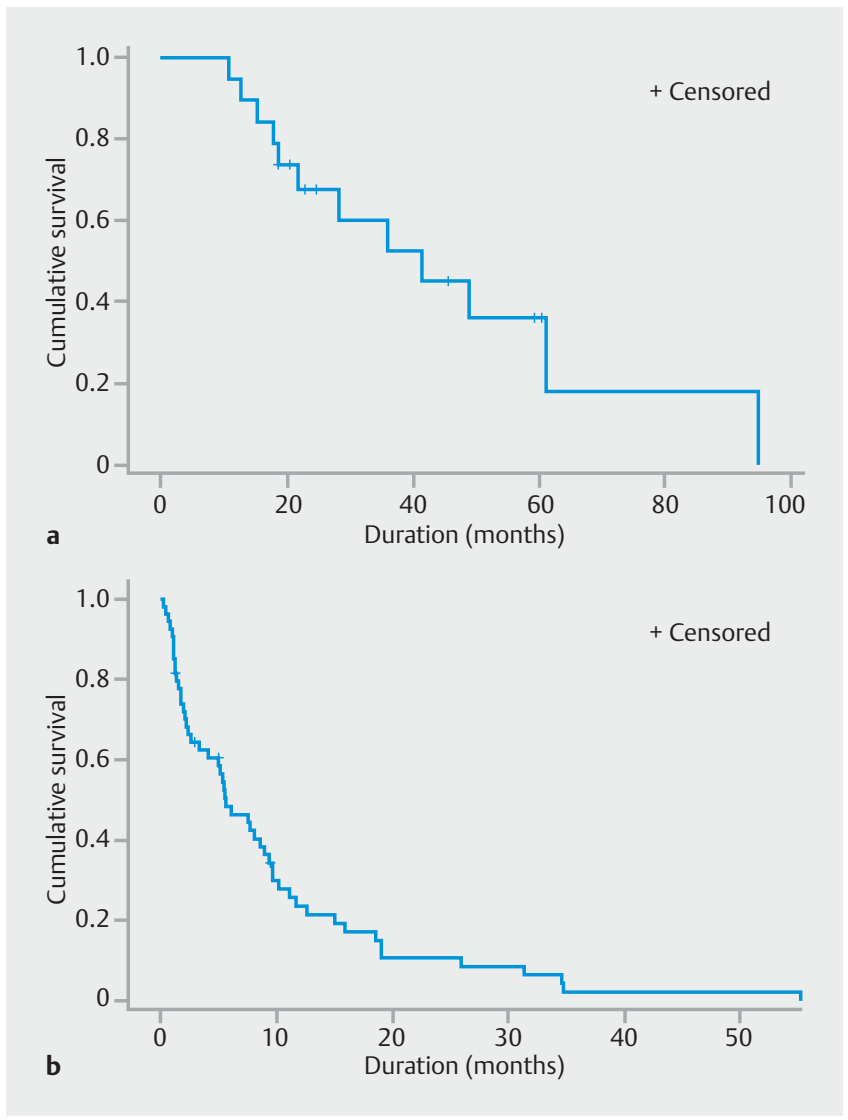

- Fig. 2 Kaplan-Meier survival curves. a In patients eligible for surgery ( $n=19$, median survival 41.5 months; $95 \% \mathrm{Cl}$ : 18.7-94.8). b In inoperable patients ( $n=54$, median survival 5.6 months; $95 \%$ Cl: 3.3-8.9).

\section{Correlation between serum and bile duct bilirubin levels}

Concentration of serum bilirubin was significantly higher in white bile patients than in patients with colored bile $(345 \pm$ $127 \mu \mathrm{mol} / \mathrm{L}$ versus $210 \pm 134 \mu \mathrm{mol} / \mathrm{L}, \mathrm{P}<0.0001)$ and there was a significant inverse correlation between serum and bile duct bilirubin levels (Pearson's correlation coefficient $r=-0.43$; $P=$ 0.0001) ( Fig.4).

\section{Discussion}

The prognostic significance of white bile as well as the pathogenic mechanisms involved in its formation are a matter of debate. Our study, the largest to date, shows that white bile in patients with inoperable malignant biliary obstruction is an independent factor associated with poorer OS. In addition, our analysis confirms that a functioning gallbladder does not prevent the formation of white bile in bile ducts. The inverse correlation between serum and bile duct bilirubin concentrations indicates that white bile in bile ducts appears progressively according to the degree of cholestasis induced by complete and prolonged obstruction. 
- Table 2 Univariate analysis of factors associated with survival in the population of patients with malignant biliary obstruction eligible for surgery $(n=19)$.

\begin{tabular}{|c|c|c|c|}
\hline Variables & $\mathbf{n}$ & $\begin{array}{l}\text { Survival time } \\
(\mathrm{mo})^{1}\end{array}$ & $\begin{array}{l}\text { Univariate } \\
\text { analysis } \\
P \text { value }\end{array}$ \\
\hline \multicolumn{3}{|l|}{ Age } & 0.61 \\
\hline \multicolumn{3}{|l|}{ Sex } & \multirow[t]{3}{*}{0.08} \\
\hline - Male & 13 & 21.8 [10.8-94.8] & \\
\hline - Female & 6 & 47.3 [18.7-61.1] & \\
\hline \multicolumn{3}{|l|}{ Type of cancer } & \multirow[t]{3}{*}{0.71} \\
\hline - Bile duct & 16 & 26.5 [10.8-94.8] & \\
\hline - Pancreatic & 3 & 21.8 [17.9-60.4] & \\
\hline \multicolumn{3}{|c|}{ Hilar obstruction } & \multirow[t]{3}{*}{0.42} \\
\hline - Yes & 3 & $59.3[41.5-61.1]$ & \\
\hline - No & 16 & $22.3[10.8-94.8]$ & \\
\hline \multicolumn{3}{|c|}{ Serum total bilirubin } & 0.81 \\
\hline \multicolumn{3}{|l|}{ White bile } & \multirow[t]{3}{*}{0.96} \\
\hline - Yes & 7 & $22.8[10.8-94.8]$ & \\
\hline - No & 12 & $26.5[12.7-61.1]$ & \\
\hline
\end{tabular}

Although initial observations of white bile date back a century [1,2], data about its clinical significance are scarce and controversial $[3,10,13]$. Most reports are anecdotal or concern small numbers of patients. The largest series was reported by Ahuja et al [3] in 2002, who compared 18 white bile patients with 17 patients with colored bile. Among patients with white bile, 15 had gallbladder cancer and three had pancreatic cancer. White bile was defined visually as translucent bile duct fluid. The mean concentration of bile duct bilirubin in these patients was $8.2 \pm 0.07 \mu \mathrm{mol} / \mathrm{L}$. Although the number of patients was small, reported survival was significantly worse in white bile patients [3]. In another study published in Korean in 2008, Jung et al [14] analyzed a series of 16 patients with white bile and 44 patients with colored bile. Data from the English abstract indicate that all patients had malignant biliary obstruction. White bile was defined as bile duct fluid with bilirubin $<25 \mu \mathrm{mol} / \mathrm{L}$. Survival analysis conducted in a subgroup of $35 \mathrm{in}-$ operable patients did not show any significant difference between patients with and without white bile.

Our study was conducted on the largest population of white bile patients so far. In contrast with Ahuja et al's study [3], in which most patients had gallbladder cancer (83\%), our series included only one patient with gallbladder cancer and an approximately equal distribution of patients with bile duct cancer and pancreatic cancer. In the small subgroup of 19 patients eligible for surgery, OS was not significantly different between patients with white bile and those with colored bile. In contrast, in

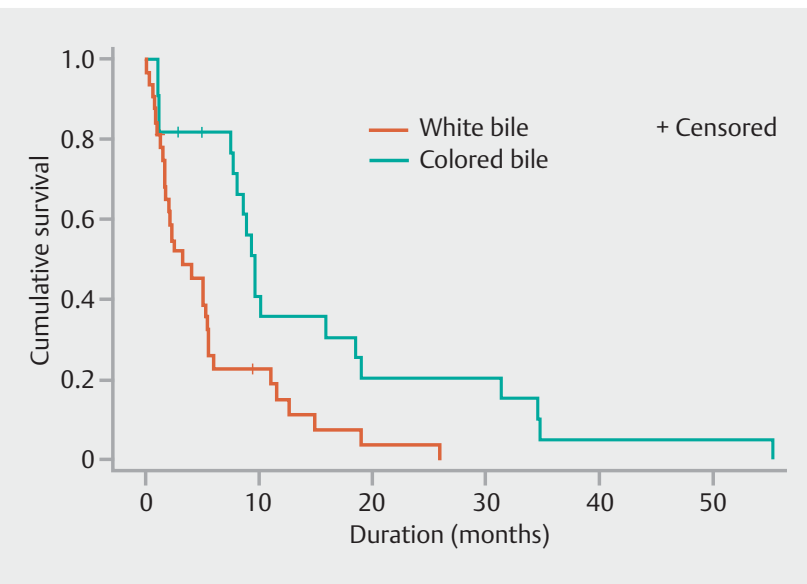

- Fig. 3 Kaplan-Meier survival curves in patients not eligible for surgery with white bile $(n=32)$ and with colored bile $(n=22)$ $(P=0.003, \log$ rank test).

the group of 54 patients with inoperable malignant biliary obstruction, the multivariate analysis demonstrated that the presence of white bile in the bile ducts was an independent factor associated with poorer OS (HR 2.3, 95\% Cl: 1.1-4.7, P=0.02) as it may reflect more severe and prolonged cholestasis due to locally advanced cancer. Other factors associated with poorer survival were the presence of mestatasis at diagnosis, which reflects advanced stage disease (HR 2.8, 95\% Cl: 1.4-5.7, P= $0.003)$ and higher serum total bilirubin (HR 1.003, , $95 \% \mathrm{Cl}$ : 1.001-1.006, $\mathrm{P}=0.01$ ).

The mechanisms of white bile formation have long been controversial. As reviewed by Elmslie et al [10], old studies pointed to the role of the gallbladder, claiming that gallbladder distal to the obstruction (outside the obstructed tract) or not functioning was a prerequisite for formation of white bile due to the lack of absorptive functions by the gallbladder [10]. Old studies in animals supported this hypothesis. In several animal models, Rous and Mc Master [11] reported that white bile appeared after prolonged common bile duct obstruction associated with obstruction of the neck of the gallbladder. The stasis bile was initially pigmented and then became progressively clear and finally colorless. In contrast, when obstructed ducts were still connected with a functioning gallbladder, stasis bile remained colored. They concluded that white bile was formed in obstructed bile ducts only in case of excluded or non-functioning gallbladder. Although clinical studies initially supported this hypothesis [1], later studies showed that white bile may appear in obstructed bile ducts with or without a functioning gallbladder $[3,10]$ and this was confirmed in our series. White bile was observed in cholecystectomized patients and in patients with gallbladder in situ, whatever the level of obstruction, above or below the cystic convergence, indicating that a functioning gallbladder does not prevent the formation of white bile in patients with malignant biliary obstruction. The inverse correlation between serum bilirubin and bile duct bilirubin suggests that the severity of cholestasis, i.e., the degree of obstruction, plays an important role in white bile formation. This 
- Table 3 Univariate and multivariate analysis of factors associated with survival in the population of patients with inoperable malignant biliary obstruction without surgery $(n=54)$.

\begin{tabular}{|c|c|c|c|c|c|}
\hline Variables & n & $\begin{array}{l}\text { Survival time } \\
(\mathrm{mo})^{1}\end{array}$ & $\begin{array}{l}\text { Univariate } \\
\text { analysis } \\
P \text { value }\end{array}$ & Multivariate analysis & \\
\hline & & & & $\mathrm{HR}(95 \% \mathrm{Cl})$ & $P$ value \\
\hline \multicolumn{3}{|l|}{ Age } & 0.69 & & \\
\hline \multicolumn{3}{|l|}{ Sex } & \multirow[t]{3}{*}{0.11} & & \\
\hline - Male & 28 & $6.7[0.2-55.2]$ & & & \\
\hline - Female & 26 & $5.0[0.6-34.6]$ & & & \\
\hline \multicolumn{3}{|l|}{ Metastasis } & \multirow[t]{3}{*}{0.002} & & \multirow[t]{3}{*}{0.003} \\
\hline - Yes & 37 & $3.3[0.2-34.6]$ & & $2.8[1.4-5.7]$ & \\
\hline - No & 17 & $11.6[1.2-55.2]$ & & 1 & \\
\hline \multicolumn{3}{|l|}{ Type of cancer } & \multirow[t]{3}{*}{0.98} & & \\
\hline - Bile duct & 25 & $5.0[0.2-34.7]$ & & & \\
\hline - Pancreatic & 29 & $6.1[0.6-55.2]$ & & & \\
\hline \multicolumn{3}{|l|}{ Hilar obstruction } & \multirow[t]{3}{*}{0.66} & & \\
\hline - Yes & 7 & $5.1[0.4-34.7]$ & & & \\
\hline - No & 47 & $5.4[0.2-55.2]$ & & & \\
\hline \multicolumn{3}{|l|}{ Serum total bilirubin } & $<0.0001$ & $1.003[1.001-1.006]$ & 0.01 \\
\hline \multicolumn{3}{|l|}{ White bile } & \multirow[t]{3}{*}{0.003} & & \multirow[t]{3}{*}{0.02} \\
\hline - Yes & 32 & $2.9[0.2-25.9]$ & & $2.3[1.1-4.7]$ & \\
\hline - No & 22 & $9.1[1.1-55.2]$ & & 1 & \\
\hline
\end{tabular}

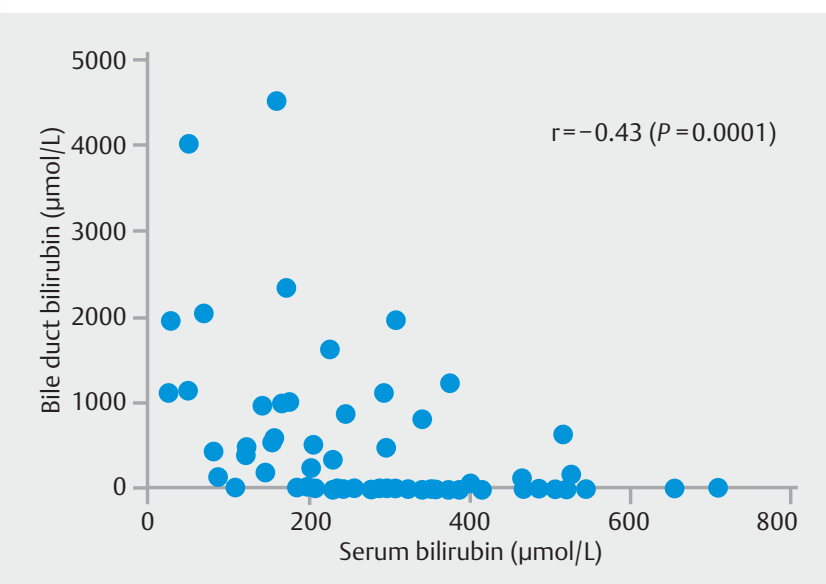

Fig. 4 Correlation between serum total bilirubin and bile duct total bilirubin.

should be brought in line with the role of the pressure within obstructed bile ducts. Experimental studies in animal models have reported that bile flow in obstructed bile ducts is main- tained up to a certain level of pressure variable according to animal species. Above this level, bile flow decreases and rapidly stops, resulting in a reverse flow and regurgitation into the blood and lymphatics. At that point, the colored bile is replaced by the colorless fluid secreted by cholangiocytes, which is devoid of bilirubin and biliary acids [15].

The main limitation of this study is inherent in its retrospective nature. The risk of bias is reduced by multivariate analysis but it cannot be completely neutralized. The lack of standardized monitoring of serum bilirubin levels after biliary decompression did not allow us to study the kinetics of bilirubin decrement, which may be impaired or slowed down in patients with white bile [3].

\section{Conclusion}

In conclusion, this study demonstrated that the presence of white bile within the bile ducts of patients with inoperable malignant biliary obstruction is an independent factor associated with OS. The presence of white bile in these patients reflects severe cholestasis due to a prolonged and tight biliary obstruction. The lack of a gallbladder is not a prerequisite for the for- 
mation of white bile, which may be observed whatever the level of biliary obstruction.

\section{Competing interests}

The authors declare that they have no conflict of interest.

\section{References}

[1] Judd ES, Lyons JH. White bile in the common bile duct. Ann Surg 1923; 77: 281-292

[2] Edington GH, McCallum G. The occurrence of "White Bile" in gallstone obstruction: note of a case with histological note. Glasgow Med J 1930; 114: 257-264

[3] Ahuja V, Garg PK, Kumar D et al. Presence of white bile associated with lower survival in malignant biliary obstruction. Gastrointest Endosc 2002; 55: 186-191

[4] Neilan RE, Groce JR, Jalil S et al. White bile (with video). Gastrointest Endosc 2007; 66: 180-181

[5] Gremida A, Rustagi T. White bile in malignant biliary obstruction: a poor prognostic marker. Clin Endosc 2018; 51: 109-110
[6] Ahuja V, Garg PK, Tandon RK. Of "horned toads"and "horned frogs". Gastrointest Endosc 2002; 56: 783

[7] Yarze JC. White bile: a "clear" misnomer. Gastrointest Endosc 2002; 56: 782-783

[8] Griffiths DB, Haber MH, Rees KR et al. Analysis of white bile in a case of cholangiocarcinoma of the hepatic ducts. J Pathol Bacteriol 1963; 85: 389-393

[9] Bouchier AD, Cooperband SR. The characteristics of "white bile" . Gastroenterology 1965; 49: 354-359

[10] Elmslie RG, Thorpe MEC, Colman JVL et al. Clinical significance of white bile in the biliary tree. Gut 1969; 10: 530-533

[11] Rous P, McMaster PD. Physiological causes for the varied character of stasis bile. J Exp Med 1921; 34: 75-95

[12] Flint ER. Obstructions of the common bile duct. Br Med J 1937; 2: 253-256

[13] Imbert-Bismut F, Messous D, Thibault $V$ et al. Intra-laboratory analytical variability of biochemical markers of fibrosis (Fibrotest) and activity (Actitest) and reference ranges in healthy blood donors. Clin Chem Lab Med 2004; 42: 323-333

[14] Jung JT, Kim HG, Han J et al. [Clinical significance of white bile (bilirubin-free bile) in malignant bile duct obstruction]. Korean J Gastroenterol 2008; 52: 91-96 Korean

[15] Hashmonai M, Kam I, Schramek A. The etiology of "white bile" in the biliary tree. J Surg Res 1984; 37: 479-486 